Products and Services In Practice is provided to readers using text and images from the manufacturer, supplier or distributor and does not imply endorsement by $B D J$ In Practice. Normal and prudent research should be exercised before purchase or use of any product mentioned.

Please send product and services news through to David Westgarth, BDJ In Practice via: David.Westgarth@bda.org

\section{Simple, fast and effective}

EasyReview is the easy way to get more Google reviews - so sign up for your 1-month free trial today.

Real results from practices already using EasyReview:

$\rightarrow$ Practice A in Poole went from 8 to 24

Google reviews in two weeks

$\rightarrow$ Practice B in Glasgow achieved 32 5-star Google reviews in three weeks

$\rightarrow$ Practice $\mathrm{C}$ in Leeds saw a $7 \%$ increase in Google reviews in just 24 hours! EasyReview has been designed exclusively for dentists and links to your current practice management software. There is no contract, no minimum term. Just more Google reviews, guaranteed!

To get your 1-month free trial of EasyReview visit www.easyreview.dental or email enquiries@dental-design.co.uk or call 01202677277 .
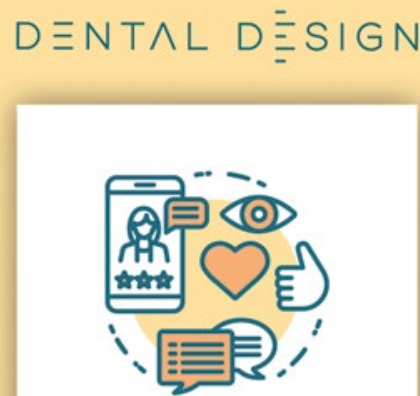

$90 \%$ OF CONSUMERS

READ REVIEWS

BEFORE VISITINC

A BUSINESS

(由) EASYREVIEW

\section{Registration is now open!}

Registration for the British Dental Conference and Dentistry Show 2020 is officially open!

Now you can secure your place at the event to make sure you don't miss out on the extensive education and networking opportunities available. A world-class speaker line-up has been accrued, with industry-leading professionals sharing their colossal collective experience and expertise.

There will also be an extensive trade floor with dental manufacturers and suppliers demonstrating their latest innovations. Whether you're looking for digital technologies, restorative materials, software programmes or training courses, there will be something for you.
The British Dental Conference and Dentistry Show 2020 takes place on 15 and 16 May at Birmingham NEC, co-located with DTS. To register, and for all the latest information, visit www.thedentistryshow. co.uk, call 02073485270 or email dentistry@closerstillmedia.com.

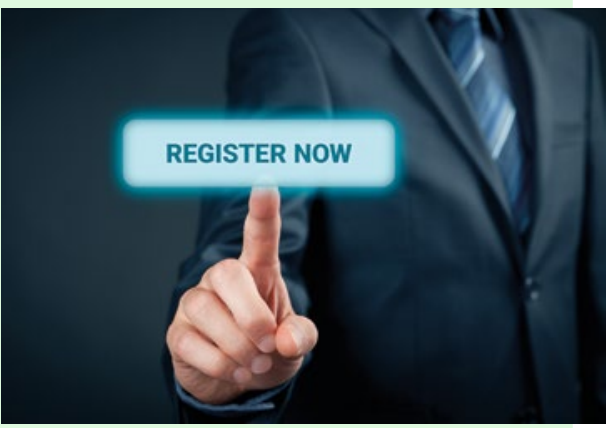

\title{
Empower the way your work
}

Are you looking for software that keeps up to date with the latest industry trends and helps you to provide a more holistic approach to care? The new Care Management Platform software from Carestream Dental is what you're looking for.

An innovative blend of industry-leading imaging capabilities, workflow focus, intuitive design and anytime, anywhere patient data access, the software is designed for the modern dental professional in every element.

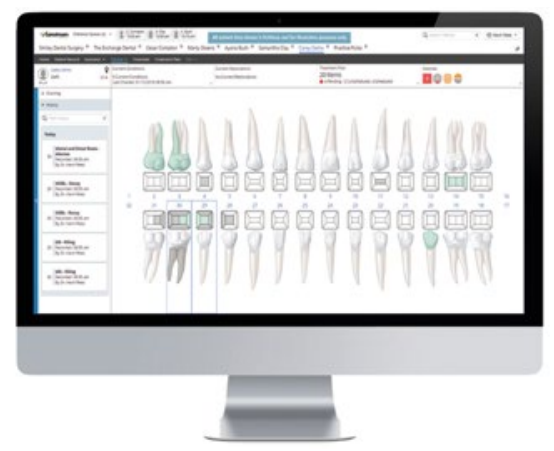

By using the software, practitioners will be able to maximise their practice's potential by exploring and implementing the latest healthcare trends. They can also increase their productivity and patient care options by making the most of the numerous functionalities that the software provides.

For more information, contact Carestream Dental on 08001699692 or visit www.carestreamdental.co.uk.

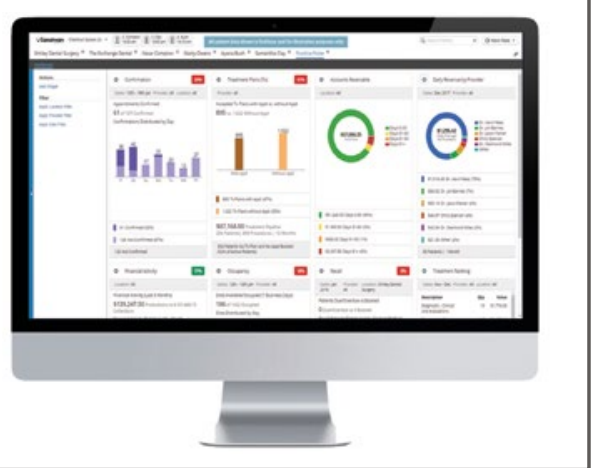

